\title{
El oráculo de Dídima: un ejemplo de las relaciones diplomáticas en época helenística
}

\author{
The oracle of Didyma: an example of diplomatic relations \\ in the Hellenistic period
}

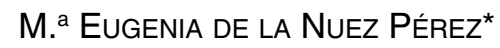

\begin{abstract}
RESUMEN
En un periodo tan complejo como la época helenística, las ciudades de Asia

Menor van a establecer una red de relaciones diplomáticas entre ellas y con

los nuevos actores del momento, las

monarquías helenísticas, a fin de garantizarse una cierta estabilidad tanto interior como exterior. En este 'juego', Mileto va a aprovechar la existencia en su territorio del oráculo de Apolo, situado en Dídima, para crear un vínculo sólido y duradero con los Seléucidas, vínculo que va más allá de la dominación territorial directa y que es un ejemplo de esas relaciones diplomáticas tan importantes tanto para los monarcas como para las ciudades.
\end{abstract}

\section{PALABRAS CLAVE:}

Dídima, Seléucidas, Asia Menor, oráculos, política.

\begin{abstract}
The Hellenistic period is a very complex period, especially in Asia Minor. The Greek cities of Anatolia have to establish a system of diplomatic relations between themselves and the Hellenistic Kingdoms intending to grant their independence and stability. In this paper, we will study the example of Miletos, which employed the sanctuary of Didyma to establish diplomatic relations with the Seleucids, a very strong link which is a good example of the Hellenistic diplomacy.
\end{abstract}

\section{KEYWORDS:}

Didyma, Seleucids, Asia Minor, oracles, politics.

* Département LE/LEA, Université Michel de Montaigne Bordeaux 3 (Domaine Universitaire, 33607 Pessac Cedex, France). E-mail : mdelanuez@ hotmail.com.

Artículo basado en la comunicación leída el 27 de Mayo de 2009, en la VIII edición del Encuentro de Jóvenes Investigadores de Historia Antigua de la Universidad Complutense de Madrid. 
El periodo comprendido entre 334 y 133 a.C. - es decir, entre el paso de Alejandro por Asia Menor y la conversión de ésta en provincia romana- es una época de grandes turbulencias políticas para las ciudades griegas de Anatolia. A los conflictos ya existentes entre ellas hay que sumar la aparición de un nuevo actor político: las monarquías. Éstas, en sus luchas para crearse un territorio propio, van a convertir las regiones orientales en un campo de batalla casi constante en el que tanto los reyes como las ciudades tienen mucho que ganar y que perder. Para los primeros se trata de crear sus reinos, para las segundas de conservar su libertad y su autonomía. No es de extrañar que sea en este momento cuando asistamos a un incremento de las relaciones diplomáticas no sólo entre ciudades sino también entre éstas y los monarcas. En el caso de este último tipo, las labores de evergesía serán uno de sus pilares básicos por cuanto eran consideradas como una de las 'obligaciones' de los monarcas por el simple hecho de serlo.

Este artículo presenta el caso de las relaciones establecidas entre el santuario de Dídima y la ciudad de Mileto por un lado, y la dinastía Seléucida por otro, ya que nos parece un claro ejemplo de la manera en que eran entendidas tanto las relaciones con los monarcas como la función de benefactor ejercida por los mismos. Se trata al mismo tiempo de un caso especial, ya que los lazos que unirán a las dos partes serán muy longevos - desde la fundación de la dinastía a fines del siglo IV a.C. hasta el final de la misma en el siglo II a.C.- y ello teniendo en cuenta que el dominio efectivo de los monarcas sobre la ciudad no será ni continuo ni de larga duración.

\section{DÍDIMA/MILETO Y LOS SELÉUCIDAS: LOS ORÁCULOS}

Una inscripción datada en 246 a.C. y recogida por Welles en su obra clásica sobre la correspondencia real en época helenística (1934), nos recuerda los motivos por los cuales los Seléucidas mantienen en ese momento, y han mantenido desde siempre, unas relaciones privilegiadas con Dídima, y por extensión con Mileto. Se trata de una carta enviada por Seleuco II al pueblo milesio para agradecerle los honores que le habían sido concedidos con motivo de su ascensión al trono. En ella, el rey recuerda que tanto sus antepasados como su padre han colmado de dones a la ciudad debido a los oráculos dados por Apolo en Dídima y a los lazos de parentesco que les unen con el dios (Welles 1934: n. ${ }^{\circ} 22$, líneas 4-6).

En efecto, las fuentes han conservado el recuerdo de una serie de oráculos dados a Seleuco, fundador de la dinastía, los cuales, con independencia de su autenticidad, pasaron a formar parte, como demuestra la inscripción, del discurso de los Seléucidas en sus relaciones con la ciudad y el oráculo. Estos oráculos habrían sido dados por el dios como respuesta a varias consultas hechas por el fundador de la dinastía. La primera habría sido hecha en 334 a.C., en el momento del paso de Alejandro cuando Seleuco no era más que un oscuro oficial del ejército. A su pregunta, que no ha llegado hasta nosotros, el dios habría respondido: «No te 
afanes en volver a Europa; Asia será mucho mejor para ti» (Apiano 12.56.283)1. Teniendo en cuenta que en esa fecha, según las fuentes, el oráculo no funciona$\mathrm{ba}^{2}$, los historiadores, guardando todas las reservas posibles, han considerado mejor fechar la consulta en otro momento más plausible sobre el cual volveremos.

Una segunda consulta, o quizá la primera, habría tenido lugar hacia 313 a.C., cuando Seleuco se encontraba combatiendo en Siria y Asia Menor bajo las órdenes de Tolomeo, quien años antes le había acogido cuando Antígono le expulsara de Babilonia en 316 a.C. ${ }^{3}$. Mileto, por su parte, acababa de recuperar la libertad gracias a Antígono, quien ese año había expulsado al tirano Asandros, sátrapa de Caria y aliado de Tolomeo. Tampoco esta vez conocemos la pregunta, sin embargo el dios responderá refiriéndose al consultante como rey Seleuco y prometiéndole una corona real después de la campaña en la que está inmerso. Para ratificar este glorioso futuro, Seleuco habría soñado, poco después, que Alejandro habría dado su aprobación sonriendo ante esta eventualidad (Diod. 19.90.3-4; Parke 1985: 45). Por último, una tercera consulta y un tercer oráculo estarían en el origen de la construcción del santuario de Apolo en Dafne, cerca de Antioquía, iniciada en torno a 301 a.C. (Libanio 9.303).

En los tres casos, los historiadores no parecen haber dudado tanto del hecho de la consulta como de las respuestas dadas, supuestamente, por el oráculo. Y, sin embargo, podemos establecer una cierta secuencia en todos ellos, una secuencia que parece apuntar a la creación de la legitimidad de la monarquía seléucida y a la asociación a la misma del santuario de Dídima. Así, en 312 a.C., un año después de la predicción de su futura corona, Seleuco va a revelar durante la batalla de Gaza un sueño que su madre le habría contado antes de partir con Alejandro, según el cual sería hijo de Apolo (Justino 15.4.3; Grainger 1990: 2). El dios habría yacido con ella y como signo de esa noche habría dejado un anillo con un ancla sobre la cabecera de la cama. Otras tradiciones añaden que Seleuco tenía esa marca en un muslo y como él todos sus descendientes. Aún más significativo, cuando Seleuco entre en Babilonia en 311 a.C., ese año será considerado el primero de la era de Seleuco, es decir, el primero de su reinado. Aunque es cierto que no va a tomar el título de basileus, ni su equivalente persa, hasta el 305 a.C., ya se consideraba como tal desde de esa fecha, ya que los documentos de Babilonia de 305 a.C. están fechados en el año 7 de Seleuco (Boiy 2004: 136 y 139).

Por supuesto, el oráculo ha podido ser una invención posterior, para justificar el interés del monarca por el santuario; no obstante la coherencia de los acontecimientos es significativa. No debemos olvidar que los territorios de Seleuco se encuentran en la zona oriental, que Babilonia es el centro de su imperio, que sus súbditos son iranios, principalmente, pero también mesopotamios y sirios. En tanto que rey, su política sigue tanto el camino abierto por Alejandro - él es el único que no

1 Traducción de A. Sancho Royo, Madrid, 1980.

2 El oráculo dejó de funcionar en 494 a.C. y guardó silencio, según las fuentes, hasta el paso de Alejandro por la ciudad en 334 a.C.: Estrabón, citando a Calístenes (18.1.43); ver Parke (1985: 41).

3 Grainger (1990: 52); Boiy (2006: 37-100, especialmente 86, cuadro 13). 
repudió a su mujer irania después de la muerte del rey-como la tradición aqueménida. De todos los santuarios de Asia Menor, Dídima es el único que puede unir esos dos mundos radicalmente opuestos. Por un lado, los Bránquidas habían sido 'fieles' a los reyes persas ${ }^{4}$; por otro, Apolo había anunciado a Alejandro su divinidad (Strab., citando a Calístenes, 18.1.43). Dídima podía ser visto como una fuente de legitimidad tanto por unos como por otros.

Por otra parte, Mileto sabía que la estatua de Apolo deportada por los persas se encontraba en los dominios de Seleuco. Obtener el regreso del 'dios' era algo que, posiblemente, sólo pudiera lograrse estableciendo relaciones con el gobernante de las regiones orientales, para lo cual podría ser útil asociar a Seleuco a la suerte del santuario. Aun en el supuesto de que la respuesta fuera inventada por el rey para reforzar su legitimidad, Mileto y Dídima se guardaron mucho de decir lo contrario y por sus acciones posteriores podemos ver que terminaron aceptando la historia como salida del santuario. Aunque también es posible que la respuesta fuera dada efectivamente en Dídima y, en ese caso, la ciudad tomaba la iniciativa de crear unas relaciones que podían serle beneficiosas no sólo en cuanto a aumentar el prestigio de la ciudad sino también económicamente, ya que Seleuco controlaba las rutas comerciales de Oriente y este hecho podría serle de utilidad, al ser una de las ciudades comerciales más importantes de Asia Menor. Por su parte, la construcción del santuario de Dafne puede ser entendida por un lado como la afirmación de Seleuco como rey, entregándose a una de las actividades que los aqueménidas esperaban de sus soberanos - la de constructores y/o reconstructores de templos ${ }^{5}$ - . Y por otro lado, como una manera de extender el prestigio de Apolo y del santuario de Dídima en el exterior.

El último oráculo es el más controvertido, por eso lo hemos dejado para el final. Se trata del único cuyas palabras han sido conservadas por las fuentes. «No te afanes por volver a Europa, Asia será mucho mejor para ti» habrían sido las palabras de Apolo consultado por Seleuco sobre sus acciones en el futuro. Al principio datado en 334 a.C., en la actualidad se piensa que estas palabras, de haber sido pronunciadas, lo fueron con probabilidad en 281 a.C. cuando Seleuco se preparaba a pasar a Europa para luchar por sus pretensiones a la corona de Macedonia, el sueño - confeso o no- de todos los Diadocos ${ }^{6}$. Estas pretensiones llevarían a los Diadocos, y Seleuco entre ellos, a buscar una legitimación a su posición que les llevase a acercarse lo más posible a Alejandro y a supuestos ancestros divinos, de ahí, probablemente, sus relaciones con Dídima7. En cuanto al oráculo de 281

${ }^{4}$ Conocemos, por ejemplo, la intervención del oráculo a favor de los persas en el asunto de la rebelión de Pacties: Briant (1996: 47-48). Sobre los Branquidas y su trágico destino: Parke (1985: 59-68).

5 Sherwin-White (1987: 1-31, en especial 9). Antíoco I, en un documento escrito en acadio y encontrado en Babilonia, copia las fórmulas de los documentos de fundación neobabilonios y declara: [...] I formed with my august hands (when I was still) in the country of Hatti (namely in Syria) the first brick for Esagila and Ezida with the finest oil and brought (it with me) for the laying of the foundations of Esagila and Ezida. Teixidor (1990: 66-78, en especial 72).

6 Parke (1985: 45); Günter (1971: 70). Para las ambiciones a la corona de Macedonia: Bosworth (2002: 246).

7 Alejandro habría iniciado la tradición al decirse hijo de Zeus. Tolomeo se dirá también hijo de Zeus y hermano, pues, de Alejandro: Koenen (1993: 25-115, en especial 44 y 50). En un artículo reciente, P. 
a.C. se trataría, pues, de una profecía creada probablemente después del asesinato del rey. Aunque también puede ser interpretada como un aviso cifrado de la ciudad al que, desde hacía años, se había convertido en su máximo benefactor (Haussollier 1902: 34).

\section{LOS SELÉUCIDAS Y DÍDIMA/MILETO: LA EVERGESIA}

Esa es la palabra que conviene para referirse a los Seléucidas cuando se trata de sus relaciones con la ciudad y el santuario, ya que su dominio efectivo sobre la región no comenzará hasta 281 a.C. y no será ni continuo ni duradero. Aunque los primeros pasos de estas relaciones son difíciles de establecer, como hemos visto, las consecuencias materiales de las mismas serán bien visibles y provechosas, sobre todo para el santuario y para la ciudad.

Así, en 300 a.C. una primera embajada real va a abandonar Babilonia con destino a Mileto. El objetivo parece haber sido la devolución de la estatua de Apolo a su 'casa'8. Es cierto que no conocemos los detalles de esta devolución, pero una inscripción datada en 299/8 nos informa de la existencia de atenciones por parte de Seleuco al santuario ${ }^{9}$, atenciones entre las cuales quizá pueda incluirse esta devolución. Si tenemos en cuenta que los trabajos en Dafne habían comenzado quizá un año antes y que los planes de Seleuco le llevan cada vez con más frecuencia a interesarse por los asuntos de Asia Menor (Grainger 1990: 164), esta embajada es de lo más significativa. Accediendo al que podía ser el anhelo más intenso de los habitantes de Mileto, Seleuco podía ganarse su fidelidad y su apoyo incondicionales. Además, se convertía en el benefactor del santuario, enlazando así los comportamientos esperados tanto en los monarcas aqueménidas como en los reyes helenísticos ${ }^{10}$.

Apenas dos años más tarde, una vez el dios instalado de nuevo en su casa, Seleuco y su familia - tanto Apama, su esposa, como Antíoco, su hijo- van a enviar nuevas embajadas para, esta vez, contribuir a los trabajos de reconstrucción del santuario. Así, los beneficios del pórtico comercial construido por inspiración de Antíoco debían servir para financiar las obras en el santuario (Rehm 1958: n. ${ }^{\circ} 479$, líneas 5-14). La fecha de estas embajadas y de estas labores de evergesia es 299/8 a.C., un momento clave para las aspiraciones de Seleuco en Asia Menor y en Macedonia, ya que es la fecha de su matrimonio con Estratonice, matrimonio que

Debord, sin negar la importancia de Dídima y de Apolo para los Seléucidas, señala la posibilidad de una atención importante de la dinastía al culto de Zeus, en especial en la Tetrápolis siria: Debord (2003: 281304, en especial 304).

8 La estatua fue devuelta, según Pausanias (1.16.3; 8.46.3), por Seleuco.

9 Rehm (1958: $n .^{\circ} 479$, líneas 2-5). Las mismas consideraciones encontramos en el decreto honorífico votado a favor de Apama, madre de Antíoco y esposa de Seleuco, datado en el mismo año (299/8 a.C.): Günter (1971: 23-24); Rehm (1958: n. ${ }^{479}$, líneas 5-8).

10 Bringmann (1993: 7-24, en especial 8); Gauthier (1985: 39-40). Para este carácter en los monarcas aqueménidas: Sherwin-White (1987: 1-31, en especial 9). Para la adaptación de la monarquía a los cánones tradicionales de Oriente: Kuhrt (1996: 41-54, en especial 42). 
sella la alianza entre los Seléucidas y Demetrio, padre de la novia, y cuyas negociaciones tendrán lugar en Mileto, dominada en estos momentos por éste último ${ }^{11}$.

Demetrio será acogido en la ciudad años más tarde (287-285 a.C.) por Eurídice, la esposa repudiada de Tolomeo, que ha encontrado refugio aquí (Haussollier 1902: 29-30). Y Mileto será el lugar donde se case con Tolemais, hija de Eurídice, en un pacto llevado a cabo gracias a la intervención de Seleuco (Haussollier 1902: 29). Éste, en 288/7 a.C. —es decir, un año antes de la llegada de Demetrio-, había enviado una nueva embajada a Dídima, esta vez con ofrendas suntuosas para los dioses y con las víctimas necesarias para hacerles sacrificios tras la consulta al oráculo llevada a cabo por su enviado (Rehm 1958: n. ${ }^{\circ} 424$, líneas 61-62).

Si analizamos la progresión de los actos del rey, podemos darnos cuenta de que Seleuco parece intentar asociar el renacimiento del santuario a su persona y a su dinastía. Primero devuelve la estatua del dios, lo que significa, en cierto modo, la vuelta de Apolo mismo y la continuidad del culto. Luego se preocupa de dotar al dios de una 'casa' conveniente proveyendo a la ciudad de recursos para las obras. $\mathrm{Y}$, finalmente, envía ofrendas, ordena hacer una consulta al oráculo y hacer sacrificios a los dioses, prueba de que la actividad cultual está totalmente restablecida. Si ese era su objetivo, podemos decir que el rey lo cumplió ampliamente ya que, desde 281 a.C. - si no antes-, Apolo será reconocido como el ancestro de la dinastía, no sólo por los Seléucidas sino también por las ciudades de Asia Menor, como lo muestran dos inscripciones de llion y un himno de Eritras ${ }^{12}$.

Tras la muerte de Seleuco, sus sucesores continuarán distinguiendo el santuario y la ciudad con su benevolencia en «virtud de los oráculos dados a sus ancestros» y como continuidad de la labor comenzada por los mismos. Así, tenemos constancia de dones y regalos hechos al santuario hasta el reinado de Antíoco IV, muerto en 164 a.C. (Bringmann y von Steuben 1995: $n .^{\circ} 284$, II), lo que significa que las relaciones entre Dídima y la dinastía van a llegar hasta el fin de la misma, siendo las más longevas de cuantas estableciera el santuario con los monarcas helenísticos.

Así, los reyes no actúan sólo para mayor gloria del santuario al que, posiblemente, deben su legitimidad, sino también para asentar su posición como monarcas. De esta manera, siguiendo el ritmo habitual de las relaciones diplomáticas, a las embajadas reales se siguen las embajadas enviadas por la ciudad llevando al monarca las voluntades de los ciudadanos en forma de decreto honorífico confiado a los embajadores elegidos por el Consejo y la Asamblea (Savalli-Lestrade 2003: 17-39, en especial 19-25). El contenido de estos decretos y de las cartas reales es nuestra principal fuente de información concerniente a estas relaciones. Así, sabemos que entre los honores ofrecidos a los Seléucidas se encuentra el derecho de primacía en la consulta del oráculo (promanteia), la presidencia de los juegos en las fiestas

11 Grainger (1990: 132), sobre el matrimonio de Seleuco con Estratonice, hija de Demetrio. Este matrimonio convierte al rey en polígamo ya que, al parecer, Apama, su primera esposa y madre de Antíoco, estaba aún con vida: Bielman-Sánchez (2003: 41-61, en especial 46).

12 Para el himno: Engelmann y Merkelbach (1973: n. $\left.{ }^{\circ} 205,74 s s.\right)$. Para las inscripciones: Frisch (1975: nos. 31-2); Bringmann (2000: 82). 
principales de la ciudad, exenciones fiscales, así como coronas, estatuas y otros honores de rigor (Rehm 1958: n. ${ }^{\circ}$ 479, líneas 15-42). En una palabra, las relaciones establecidas se mueven más en el campo de la función de benefactor atribuida al monarca que en el campo de las relaciones entre una ciudad sometida y su conquistador. La misma función que será utilizada por todos los monarcas helenísticos cuando establezcan sus relaciones con las ciudades de Asia Menor.

\section{CONCLUSIONES}

En el marco de una actividad diplomática intensa, los primeros Seléucidas establecen unas relaciones duraderas con Mileto siguiendo una progresión escalonada que parece responder a sus intereses políticos e ideológicos. Los oráculos de 313 a.C. y el que hace referencia a la construcción del santuario de Apolo en Dafne aparecen, pues, claramente vinculados al reconocimiento de Seleuco como rey, reconocimiento que parece contar con el acuerdo tácito de Alejandro, hecho necesario para que estas aspiraciones sean reconocidas por todos. Después de 301 a.C. - posible fecha del inicio de la construcción de Dafne-, el rey vuelve sus ojos a Asia Menor y, a cada movimiento político de enemigos o posibles aliados que interesase a Mileto/Dídima, va a responder colmando al santuario de beneficios. Estas embajadas, aparte de su importancia religiosa, tienen una gran importancia política, ya que sirven para afirmar los lazos de la dinastía -Antíoco y Apama asociados a Seleuco- con la ciudad y el santuario. De esta manera se 'reduce' la posible influencia de los reyes rivales. Así, podemos establecer una línea continua y sólida entre 313 y 281 a.C., es decir, entre el primer oráculo y el último de los supuestamente dados a Seleuco. A partir de ese momento, las relaciones están más que afirmadas y la dinastía continuará los dones por tradición, hasta el reinado de Antíoco IV, muerto en 174 a.C. Es decir: la labor comenzada por el fundador de la dinastía llegará hasta casi la creación de la provincia de Asia en 133 a.C. cubriendo así todo el periodo helenístico.

En cuanto a Mileto, atrapada en las luchas por el control de Asia Menor, el hecho de tener un benefactor más o menos estable y atento no podía cuanto menos que favorecerla. Sobre todo si tenemos en cuenta que Seleuco no dominaba la región. No es extraño pues, que se dejara colmar de regalos que de todas maneras la beneficiaban en casi todos los aspectos: por un lado, se acrecentaba la fama del santuario; por otro, se aseguraba un estatus de ciudad libre; y finalmente se podía beneficiar económicamente tanto por los bienes materiales como por el hecho de que los Seléucidas eran los dueños de las rutas comerciales de Oriente.

\section{BIBLIOGRAFÍA}

BILDE, P.; ENGBERG-PEDERSEN, T.; HANNESTAD, L. y ZAHLE, P. eds. (1990), Religion and Religious Practice in the Seleucid Kingdom, Aarhus.

- eds. (1996), Aspects of Hellenistic Kingship, Oxford.

BIELMAN-SÁNCHEZ, A. (2003), «Régner au féminin. Réflexions sur les reines attalides et séleucides», en Prost, F. dir., 41-61. 
BOSWORTH, A. B. (2002), The Legacy of Alexander. Politics, Warfare and Propaganda under the Successors, Oxford.

BOIY, T. (2004), Late Achaemenid and Hellenistic Babylon, Leuven.

- (2006), "Aspects chronologiques de la période de transition (350-300 av. J.-C.)», en BRIANT, P. y JOANNÈS, F. dirs., 37-100.

Briant, P. y Joannès, F. dirs. (2004), La Transition entre l'Empire Achémenide et les Royaumes Hellénistiques (vers 350-300 av. J.-C.), Paris.

BRIANT, P. (1996), Histoire de l'Empire Perse. De Cyrus à Alexandre, París.

BRINGMANN, K. (1993), «The king as benefactor. Some remarks on ideal kinship in the age of Hellenism», en Bulloch, A. W.; Gruen, E. S.; Long, H. A. y Stewart, A. eds., 7-24.

- (2000), Gegen und Nehmen monarchische Wohltätigkeit und Selbstdarstellung im Zeitalter des Hellenismus, Berlín.

BRINGMANN, K. y STEUBEN, H. von (1995), Schenkungen hellenistischer Herrscher an griechische Städte und Heiligtümer. Teil I. Zeugnisse und Kommentar, Berlín.

BULLOCH, A. W.; GRUEN, E. S.; LONG, H. A. y STEWART, A. eds. (1993), Images and Ideologies: Self-Definition in the Hellenistic World, Berkeley.

DEBORD, P. (2003), «Le culte royal chez les Séleucides», en Prost, F. dir., 281-304.

ENGELMANN, H. y MERKELBACH, R. (1973), Die Inschriften von Erythrai und Klazomenai II, Bonn.

FRISCH, P. (1975), Die Inschriften von llion, Bonn.

GAUTHIER, C. (1985), Les Cités Grecques et Leurs Bienfaiteurs (IV - ler siècles av. J.-C.), París.

GRAINGER, J. D. (1990), Seleuco Nikator. Constructing a Hellenistic Kingdom, London.

GÜNTER, W. (1971), Das Orakel von Didyma in hellenisticher Zeit. Eine Interpretation von Stein-Urkunden, Tübingen.

HAUSSOLLIER, B. (1902), Etudes sur l'histoire de Milet et du Didymeion, Paris.

KOENEN, L. (1993), «The Ptolemaic king as a religious figure», en Bulloch, A. W.; Gruen, E. S.; Long, H. A. y Stewart, A. eds., 25-115.

KURHT, A. (1996), «The Seleucid Kings and Babylonia: new perspectives on the Seleucid realm in the East», en Bilde, P.; Engberg-Pedersen, T.; Hannestad, L. y Zahle, P. eds., 4154.

PARKE, H. W. (1985), The Oracles of Apollo in Asia Minor, London.

- (1985), «The massacre of the Branchidae», JHS 105, 59-68.

PROST, F. dir. (2003), L'Orient Méditerranéen de la Mort d'Alexandre aux Campagnes de Pompée, Rennes.

REHM, A. (1958), Die Inschriften von Didyma, Berlin.

SAVALLI-LESTRADE, I. (2003), «L'èlaboration de la décision royale dans l'Orient hellénistique», en Prost, F. dir., 7-39.

SHERWIN-WHITE, S. (1987), "Seleucid Babylonia: a case study for the installation and development of Greek rule», en Sherwin-White, S. y Kurht, A. eds., 1-31.

SHERWIN-WHITE, S. y KURHT, A. eds. (1987), Hellenism in the East, London.

TEIXIDOR, J. (1990), «Interpretations and misinterpretations of the East in Hellenistic times», en Bilde, P.; Engberg-Pedersen, T.; Hannestad, L. y Zahle, P. eds., 66-78.

WELLES, C. B. (1934), Royal Correspondence in the Hellenistic Period, New Haven. 